\title{
Maxillary Cuniculatum Carcinoma: a Case Report and Literature Review
}

\author{
Carcinoma Cuniculatum Maxilar: Presentación de un Caso y Revisión de la Literatura
}

Ilson Sepúlveda*; Loreto Spencer"; Enrique Platin ${ }^{*+*}$ \& Francisco Bravo ${ }^{*+* * *}$

SEPÚLVEDA, I.; SPENCER, L.; PLATIN, E. \& BRAVO, F. Maxillary cuniculatum carcinoma: a case report and literature review. Int. J. Odontostomat., 6(3):281-284, 2012.

ABSTRACT: We report on a patient who presented to our clinic with a volume increase and pain at left maxillary region. A biopsy of the area was performed and the lesion was diagnosed as differentiated squamous cell carcinoma of the type cuniculatum. Due to the size of the tumor and compromise of vital intracraneal structures it was decided to perform surgical drainage and later is evaluated because of the tumor persistence to ultimately use palliative care.

KEY WORDS: squamous cell carcinoma, cuniculatum, computer tomography, tumor, sinonasal.

\section{INTRODUCTION}

Carcinoma cuniculatum (CC) is a rare variant of squamous cell carcinoma usually involving the lower extremity. Its occurrence is extremely rare in the oral cavity and has been reported in the literature less than twenty times. First described by Aird et al in 1954 it is a variant of carcinoma showing features of squamous cell carcinoma and verrucous carcinoma and has been even described as an inverted verrucous carcinoma (Raguse et al., 2006; Allon et al., 2002; De Petris et al., 2005; Puxeddu et al., 2008) so differential diagnosis with those is necessary. For this, a close cooperation between clinician, pathologist and radiologist for the correct diagnosis is essential with regard to the correct classification and treatment (Puxeddu et al.).

Typical localization of CC is in the lower extremity specially the plantar region. It has been subsequently identified in noncutaneous regions such as the oral mucosa, oropharynx and larynx. It also has been reported in unusual sites such as the nail apparatus, pilonidal sinus, and in other noncutaneous sites such as the upper aero digestive tract including the nasal cavity and some lesions may occur off the sacral and genital region as well (Raguse et al.; De Petris et al.; Lozzi \& Peris, 2007; Lau et al., 2010).

Patients with this disease are often older in age and men seem to be predisposed. Signs and symptoms reported are of long duration pain in the region of the lesion and a slow-growing mass at that site. When skin is affected it generally appears as a slow growing painful, non-healing exophytic verruciform mass (Raguse et al.; Puxeddu et al.).

In oral cavity panoramic radiography a unilocular radiolucent lesion is shown. Computed tomography shows osteolytic lesions with irregular borders and resorption of adjacent cancellous and cortical bone. Destruction of anatomic structures, such as the nasal floor, sinus walls, and mandibular canal, have been reported in some cases (Raguse et al.; Allon et al.).

Besides the end differentiated squamous epithelium there are better differentiated areas. Many foci of neutrophilic microabscesses are observed as well. The tumor shows mild cell atypia (Raguse et al.; Allon et

\footnotetext{
Oral, Maxillofacial-Head and Neck Radiologist. Ear, Head and Neck Cancer Committe, ENT Service, General Hospital of Concepcion. Professor of Oral and Maxillofacial Radiology, Finis Terrae University School of Dentistry, Santiago, Chile.

** Physician Pathologist, Pathology Department, General Hospital of Concepción. University of Concepción School of Medicine, Concepción, Chile.

*** Professor of Oral and Maxillofacial Radiology, University of North Carolina School of Dentistry, Chapel Hill, NC. USA.

${ }^{* * * * *}$ Pre graduate Student, University of Concepcion School of Dentistry, Concepcion, Chile.
} 
al.; De Petris et al.) but frequent mitosis and lymphocytes infiltration (indicative features of carcinoma cuniculatum). CC is characterized by the presence of deep and often complex branching keratin-filled epithelial tunnels, hence its name (from the Latin word cuniculus, meaning rabbit warren). The tumor is invariably keratinizing with predominant endophytic and variably exophytic epithelial growth. In the oral mucosa, CC is reported to display occasional invasiveness through the jaw into the skin by destroying the maxillary or mandibular bone (De Petris et al.; Puxeddu et al.).

Some possible etiologic factors have been described in the literature, particularly the relationship between CC with Human Papilloma virus but results have not shown significant evidence. Other possible factors may be trauma, chronic inflammation, alcohol and tobacco consumption (36\% of the cases), but the real etiology is not well defined (Raguse et al.; Allon et al.; De Petris et al.).

$\mathrm{CC}$ is locally invasive, and metastases to regional lymph nodes have been described on rare occasion so the treatment of choice is wide local surgical excision with free margins and no lymph node dissection is performed (Raguse et al.; Kotwal et al., 2005). Besides the standard treatment of surgical excision, also Mohs' technique (serial excision for microscopic analysis) is carried out. Both therapies are associated with a high cure rate and a low recurrence rate. Alternative treatments include curettage and electrodesiccation, cryosurgery, carbon-dioxide laser therapy and radiotherapy (Lozzi \& Peris).

\section{CASE REPORT}

We have the case report of a 49 year-old male patient who is seen at the ENT service because of volume increase and pain in the left maxillary region. Clinically an extra oral volume increase at the left cheek zone is observed; intra orally there is volume increases and bone weakness when palpating the palatal zone, as well as presence of pus, inflammation and purulent fistulae. At first the patient is diagnosed with maxillary osteomyelitis. CT was performed showing a great expansive destructive and heterodense process of the left half-face (Fig. 1)

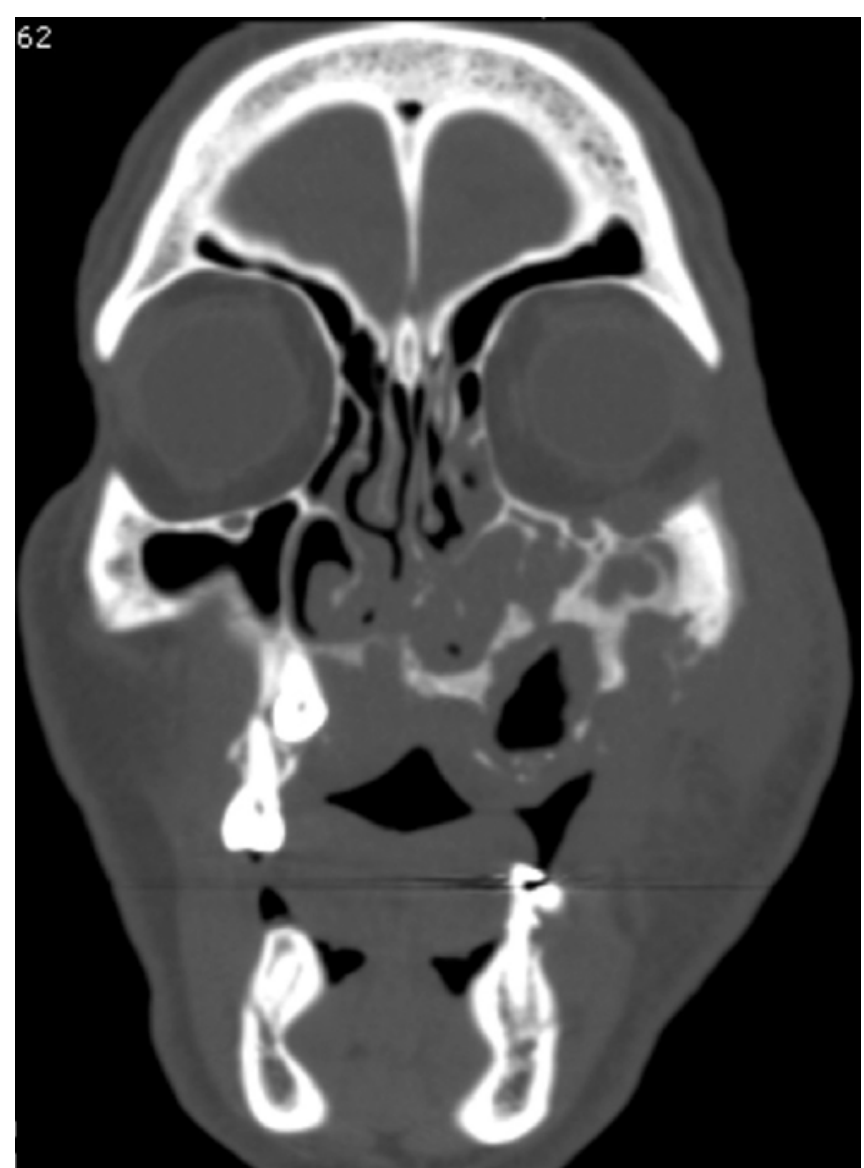

Fig. 1. CT bone window; osteolytic process in left maxillary sinus.

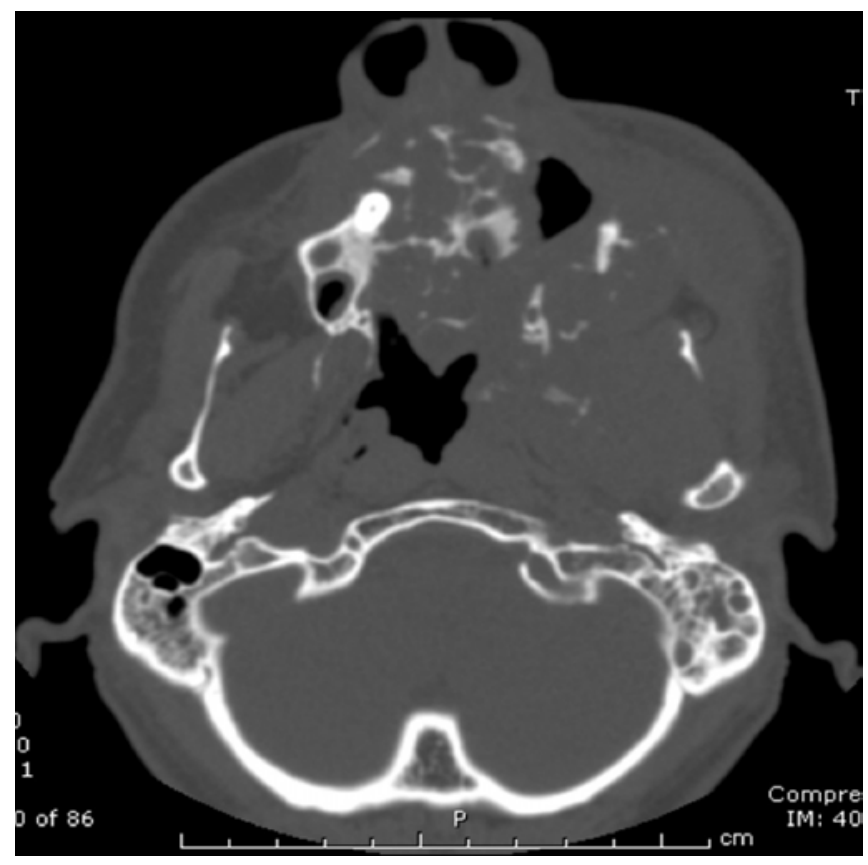

Fig. 2. CT bone window; infiltrative osteolytic compromise of hard palate. 


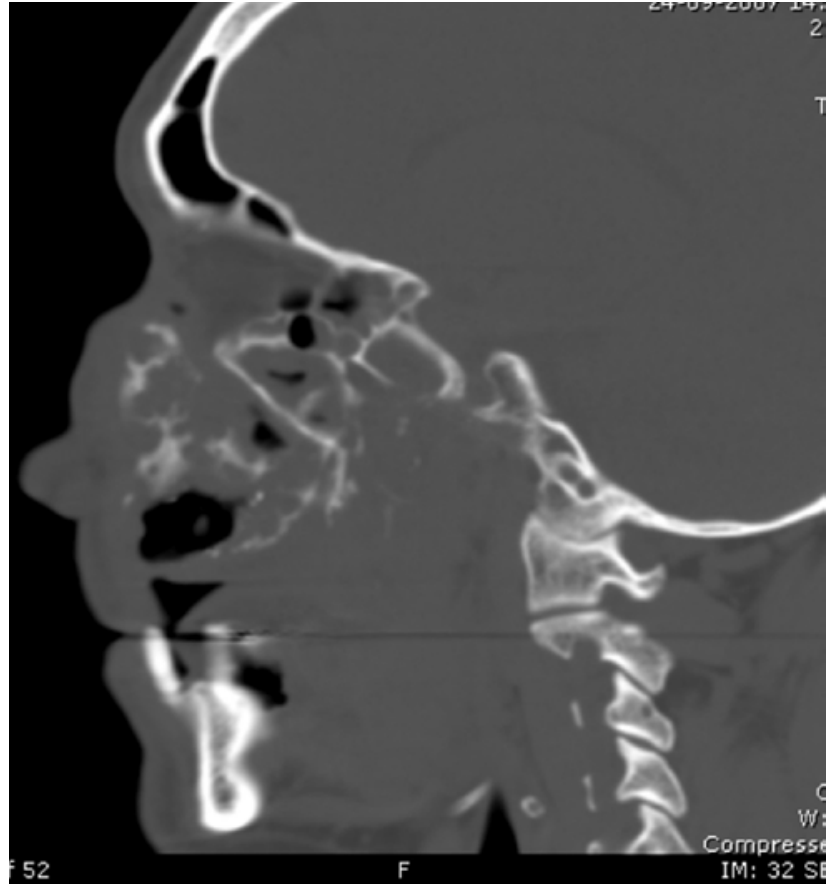

Fig. 3. CT bone window; Infiltrative compromise of orbital cavity, alveolar bone and pterigoid process.

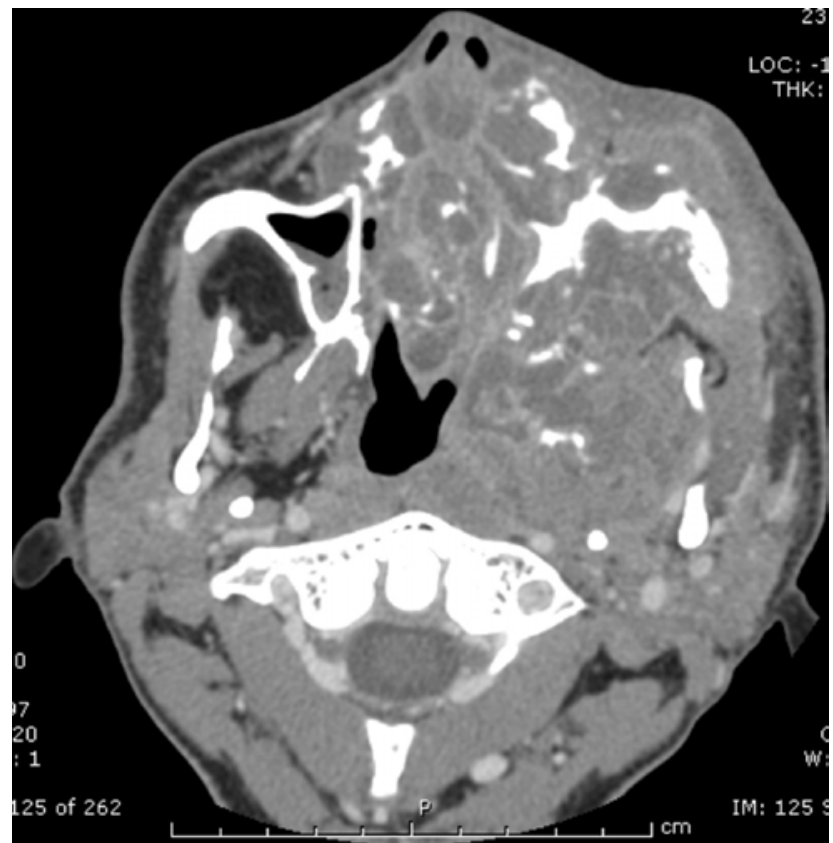

Fig. 4. Great expansive destructive and heterodense process of the left half-face with few irregular reinforcements with suggesting images of multiple necroabscesses.

which seems to have evolved from the maxillary region (Fig. 2) with current extension into the orbital cavity and into the skull with suggesting images of multiple necro abscesses (Fig. 3).

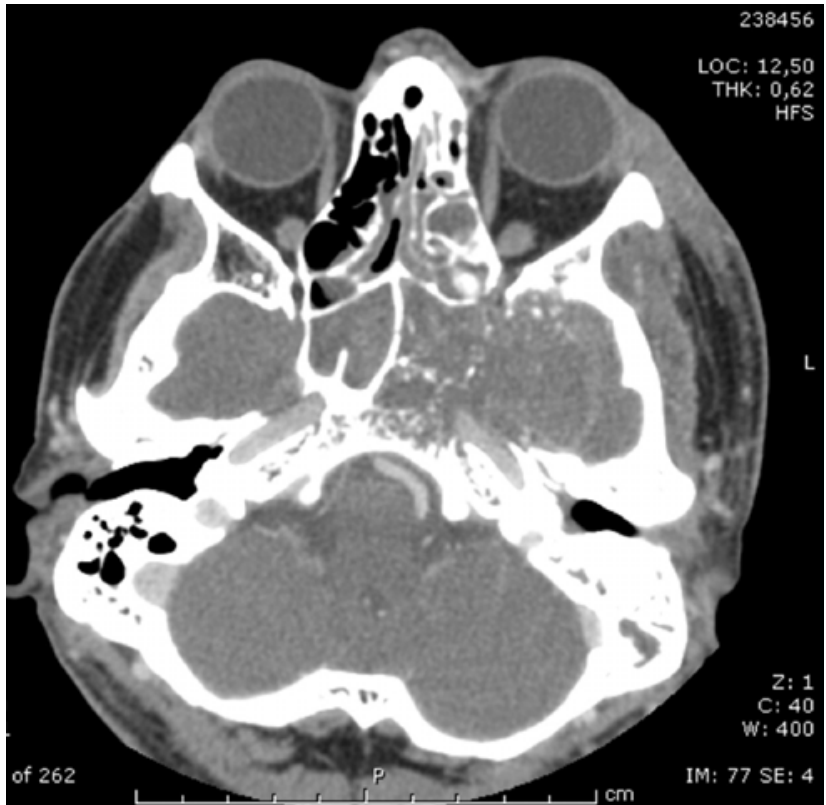

Fig. 5. Infiltrative compromise of skull base at level of left temporal lobe.

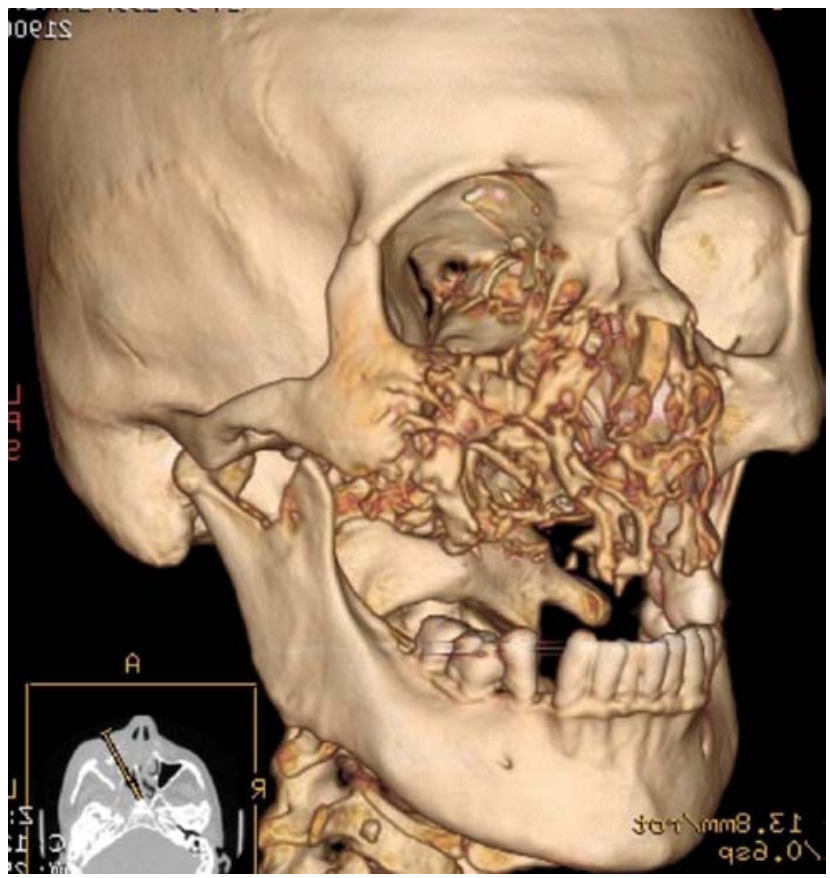

Fig.6. 3D reformat image; Infiltrative pattern like tunnel or rabbit hole.

Involvement part of the left skull base, left maxillary region, part of the anterior zygomatic bone and lower lateral wall of the left orbital cavity and sphenoid of the same side (Fig. 4) with heteromorphic masses cavitated by default with few irregular reinforcements which reach in the medial anterior region of the left temporal lobe (Fig. 5). 
The biopsy includes left neck lymph node, upper palate and vestibular mucosa. In conclusion there are no lymph nodes with metastases, at the oral and vestibular mucosa there is soft tissue and bone infiltration by well differentiated squamous cell carcinoma of the type cuniculatum, and neither tumoral lymphovascular permeation is recognized, nor respiratory mucosa with metastases (Fig. 7). Once the infectious process spread through the lower maxillary bone the patient underwent chemotherapy and radiotherapy completing these. The case is then presented to the head and neck committee, which decide to perform surgical drainage and following evaluation, palliative care is ultimately used in view of tumor persistence.

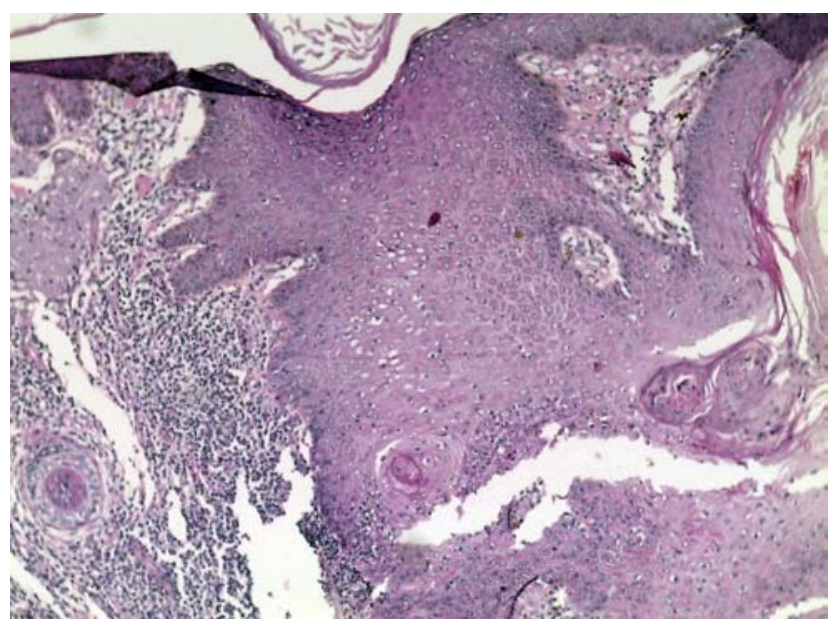

Fig. 7. H\&E Stain; Squamous ephitelial proliferation was observed with multiple Koilocytes. The tumor shows intense keratinization and chronic inflammation at the stromal level.

\section{CONCLUSION}

Carcinoma cuniculatum is a rare variant of squamous cell carcinoma, its occurrence is extremely rare in the oral cavity, it has been reported in the literature less than twenty times. Patients with this disease are often in a higher age range and men seem to be predisposed. It is characterized by the presence of deep and often complex branching keratin-filled epithelial tunnels, hence its name (from the Latin word cuniculus, means rabbit warren) Some possible etiologic factors have been described in the literature, specially your relationship with Human Papilloma virus but results have not shown significant evidence. It is locally invasive, and metastases to regional lymph nodes have been described on rare occasion. The treatment of choice is wide local surgical excision with free margins.
SEPÚLVEDA, I.; SPENCER, L.; PLATIN, E. \& BRAVO, F. Carcinoma cuniculatum maxilar: Presentación de un caso y revisión de la literatura. Int. J. Odontostomat., 6(3):281-284, 2012.

RESUMEN: Se presenta a una paciente que acudió a nuestra clínica con un aumento de volumen y dolor en región maxilar izquierda. Se realizó una biopsia del área y la lesión fue diagnosticada como carcinoma de células escamosas diferenciado de tipo cuniculatum. Debido al tamaño del tumor y el compromiso de estructuras intracraneales vitales, se decidió realizar un drenaje quirúrgico y posteriormente se evalúa la causa de la persistencia del tumor para finalmente entregar cuidados paliativos

PALABRAS CLAVE: carcinoma de células escamosas, cuniculatum, tomografía computarizada, tumor, nasosinusal.

\section{REFERENCES}

Allon, D.; Kaplan, I.; Manor, R. \& Calderon, S. Carcinoma cuniculatum of the jaw: a rare variant of oral carcinoma. Oral Surg. Oral Med. Oral Pathol. Oral Radiol. Endod., 94(5):601-8, 2002.

De Petris, G.; Lewin, M. \& Shoji, T. Carcinoma cuniculatum of the esophagus. Ann. Diagn. Pathol., 9(3):134-8, 2005.

Kotwal, M.; Poflee, S. \& Bobhate, S. Carcinoma cuniculatum at various anatomical sites. Indian J. Dermatol., 50(4):21620, 2005.

Lau, P.; Li Chang, H. H.; Gomez, J. A.; Erdeljan, P.; Srigley, J. R. \& Izawa, J. I. A rare case of carcinoma cuniculatum of the penis in a 55-year-old. Can. Urol. Assoc. J., 4(5):E12932, 2010.

Lozzi, G. P. \& Peris, K. Carcinoma cuniculatum. CMAJ, 177(3):249-51, 2007.

Puxeddu, R.; Cocco, D.; Parodo, G.; Mallarini, G.; Medda, M. \& Brennan, P. A. Carcinoma cuniculatum of the larynx: a rare clinicopathological entity. J. Laryngol. Otol., 122(10):1118-23, 2008.

Raguse, J. D.; Menneking, H.; Schollman, H. J. \& Bier, J. Manifestation of carcinoma cuniculatum in the mandible. Oral Oncol. Extra, 42(4):173-5, 2006

Correspondence to:

Dr. Ilson Sepúlveda Aguilar

Servicio de Otorrinolaringología, Cabeza y Cuello

Hospital Clínico Regional de Concepción

San Martín n 1436

Concepción

Received: 13-06-2012

CHILE

Accepted: 12-07-2012

Email:isepulvedaguilar@gmail.com 